\title{
IDENTIFIKASI MINAT MAHASISWA PROGRAM STUDI PENDIDIKAN INFORMATIKA
}

\author{
Sigit Dwi Saputro ${ }^{1}$, Ariesta Kartika Sari ${ }^{2}$, Puji Rahayu Ningsih ${ }^{3}$ \\ ${ }^{1}$ Program Studi Pendidikan Informatika \\ Universitas Trunojoyo Madura \\ Madura, Indonesia \\ Pujirahayuningsih86@gmail.com
}

\begin{abstract}
ABSTRAK
Tujuan dari penelitian ini adalah mengidentifikasi peminatan mahasiswa pendidikan informatika. Penelitian ini termasuk penelitian kuantitatif bersifat non-eksperimen dengan metode deskriptif. Data-data angka yang diperoleh berasal dari banyaknya mahasiswa yang menentukan pilihan minat terhadap ketiga bidang kompetensi tersebut yang meliputi rekayasa perangkat lunak, teknik dan komputer jaringan, dan multimedia. Data angka ini diolah ke dalam bentuk persentase dan disajikan pula dalam bentuk diagram. Adapun simpulan yang dapat dimbil dalam penelitian ini adalah: 1). Peminatan mahasiswa terhadap kejuruan multimedia lebih banyak dari pada peminatan kejuruan Teknik dan Komputer Jaringan (TKJ) maupun Rekayasa Perangkat Lunak (RPL) yaitu sebesar 55\%, dengan alasan rata - rata dikarenakan multimedia lebih aplikatif, menyenangkan, dapat bebas berkreasi dan hasilnya nyata. 2). Urutan kedua adalah peminatan kejuruan Teknik dan Komputer Jaringan (TKJ) sebesar 29\% dengan alasan rata - rata dikarenakan mahasiswa memiliki latar belakang pendidikan SMK Teknik dan Komputer Jaringan (TKJ), dan 3) Urutan terakhir adalah untuk peminatan kejuruan Rekayasa Perangkat Lunak (RPL) sebesar 16\% dengan alasan rata - rata karena mahasiswa memiliki latar belakang pendidikan SMK Rekayasa Perangkat Lunak (RPL).
\end{abstract}

Kata kunci: Peminatan, Multimedia, Teknik dan Komputer Jaringan, Rekayasa Perangkat Lunak.

\begin{abstract}
The aim of this study is to identify specialization in informatics education students. This study includes quantitative research is non-experimental descriptive method. The data obtained figures derived from the number of students determines the choice of his interest in the three areas of competence (Software Engineering, Computer Engineering and Networks, and Multimedia). The number of data to be processed into a percentage and presented in the form of a diagram. The conclusion that can be take in this study were: 1). Specialisation multimedia vocational students to more than vocational specialization Engineering and Computer Network (TKJ) and Software Engineering (RPL) that is equal to 55\%, by reasons are multimedia more applicable, fun, free to be creative and the results are tangible. 2). The second order is specialization vocational Engineering and Computer Network (TKJ) by $29 \%$ by reason are students have the educational background Engineering and Computer Network (TKJ) at vocational high School, and 3) the order of the last is for specialization vocational Software Engineering (RPL) by $16 \%$ by reason are students have the educational background Software Engineering (RPL) at vocational high School.
\end{abstract}

Keywords: Specialisation, Multimedia, Computer Engineering and Networks, Software Engineering. 


\section{Pendahuluan}

Program Studi Pendidikan Informatika merupakan bagian stake holder dari Universitas Trunojoyo Madura yang ingin bersama-sama menyukseskan tujuan besar Universitas yaitu ungul dibidang pendidikan dan riset. Pendidikan informatika menderivasi tersebut dengan visinya yaitu menjadi lembaga yang berkualitas dan menghasilkan lulusan/tenaga pendidik yang berkarakter dan kreatif di bidang pengembangan pembelajaran berbasis teknologi informasi pada akhir tahun 2020.

Sesuai dengan visi tersebut maka misi Program Studi Pendidikan Informatika yaitu 1). menyelenggarakan pendidikan dan pembelajaran untuk menghasilkan lulusan/ tenaga pendidik yang berkarakter dan kreatif di bidang pengembangan pembelajaran berbasis teknologi informasi (ti); 2). menyelenggarakan penelitian dan pengembangan ilmu untuk menghasilkan karya akademik yang unggul dan berdaya saing tinggi dalam bidang pendidikan informatika dan komputer, dan 3). menyelenggarakan kegiatan pengabdian masyarakat melalui penerapan iptek dalam bidang pendidikan informatika yang bermanfaat bagi masyarakat.

Adapun tujuan Program Studi Pendidikan Informatika yaitu meliputi 1). Menghasilkan lulusan atau tenaga pendidikan yang mampu mengembangkan pengetahuan di bidang pendidikan informatika dan terampil dalam mengembangkan pembelajaran berbasis ti; 2). Menghasilkan karya akademik melalui kegiatan penelitian dan pengembangan ilmu dalam bidang pendidikan informatika, dan 3). menghasilkan karya kreatif dalam bidang pendidikan informatika dan komputer yang bermanfaat bagi masyarakat.

Sesuai dengan Visi Misi Program Studi Pendidikan Informatika, lulusan yang dihasilkan prodi ini akan berkarir dibidang teknik komputer dan informatika baik berupa instansi pemerintah, swasta bahkan membuka peluang kerja secara mandiri. Oleh sebab itu, prodi harus menyiapkan lulusan yang berkompeten dan siap bersaing dalam dunia kerja. Peminatan mahasiswa menjadi suatu keniscayaan agar setiap lulusan terampil pada bidang-bidang keahlian tertentu.

Peminatan mahasiswa dalam penyelenggaraan pendidikan tidak sebatas pemilihan dan penetapan saja, namun juga termasuk adanya langkah lanjut yaitu pendampingan, pengembangan, penyaluran, evaluasi dan tindak lanjut. Mahasiswa dapat memilih secara tepat tentang peminatannya apabila memperoleh informasi yang memadai atau relevan, memahami secara mendalam tentang potensi dirinya, baik kelebihan maupun kelemahanya. Pendampingan dilakukan melalui proses pembelajaran yang mendidik dan terciptanya suatu kondisi lingkungan pembelajaran yang kondusif.

Berdasarkan latar belakang tersebut peneliti melakukan Identifikasi terhadap minat mahasiswa Pendidikan Informatika, yang dikhususkan dalam 3 peminatan kejuruan meliputi:

a. Multimedia

b. Tehnik dan Komputer Jaringan (TKJ)

c. Rekayasa Perangkat Lunak (RPL)

Adapun manfaat penelitian ini adalah:

a. Dapat mengetahui gambaran umum minat mahasiswa Program Studi Pendidikan Informatika.

b. Sebagai dasar pengambilan kebijakan prodi dalam pembimbingan dan pelaksanaan pelatihan sehingga menghasilkan lulusan sesuai dengan visi dan misi prodi.

\section{Metode Penelitian}

Penelitian ini termasuk penelitian kuantitatif bersifat non-eksperimen dengan metode deskriptif. Salah satu tujuan penelitian ini adalah untuk memberikan gambaran tentang persentase minat mahasiswa terhadap kompetensi di program studi pendidikan 
informatika. Salah satu jenis penelitian yang cocok adalah jenis penelitian deskriptif. Hal ini sesuai dengan yang diungkapkan oleh Siregar (2014:2) bahwa Statistik deskriptif adalah statistik yang berkenaan dengan bagaimana cara mendeskripsikan, menggambarkan, menjabarkan, atau menguraikan data agar mudah difahami. Sedangkan menurut Sugiono (2014:29) statistik deskriptif adalah statistik yang berfungsi untuk mendeskripsikan atau memberi gambaran terhadap objek yang diteliti melalui data sampel atau populasi sebagaimana adanya, tanpa melakukan analisis dan membuat kesimpulan yang berlaku untuk umum.

Data-data angka yang diperoleh berasal dari banyaknya mahasiswa yang menentukan pilihan minatnya terhadap ketiga bidang kompetensi tersebut (Rekayasa Perangkat Lunak, Jaringan, dan Multimedia). Data angka ini akan diolah ke dalam bentuk persentase dan disajikan pula dalam bentuk diagram. Dengan demikian, disimpulkan bahwa jenis penelitian ini adalah penelitian deskriptif kuantitatif, yang mana cocok untuk memberikan gambaran awal beraitan dengan identifikasi minat mahasiswa terhadap bidang kompetensi yang ada di program studi pendidikan informatika, antara lain Rekayasa Perangkat Lunak, Jaringan, dan Multimedia.

Penelitian ini bertempat di program studi pendidikan informatika, Fakultas Keguruan dan Ilmu Pendidikan, Universitas Trunojoyo Madura. Waktu yang digunakan mulai tahapan persiapan penelitian hingga penyajian hasil data adalah sekitar 4 bulan (bulan Agustus November 2015). Adapun jadwal penelitian ini disajikan pada Tabel 3.1 di bawah ini,

Populasi penelitian ini adalah seluruh mahasiswa program studi pendidikan informatika yang berasal dari angkatan 2013 sejumlah 143 mahasiswa. Sedangkan sampel penelitian diambil sebanyak 100 mahasiswa sesuai dengan ketentuan penentuan jumlah sampel dari populasi tertentu dengan taraf kesalahan 5\% (Sugiyono, 2014:71).

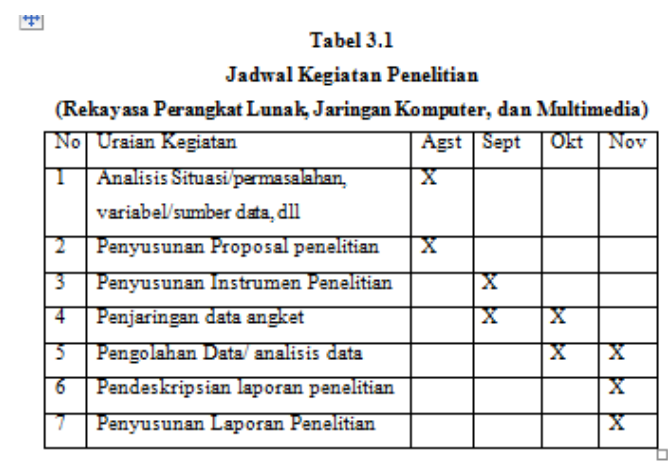

Prosedur dalam penelitian ini disajikan pada gambar 3.1 diagram alir penelitian identifikasi minat sebagai berikut

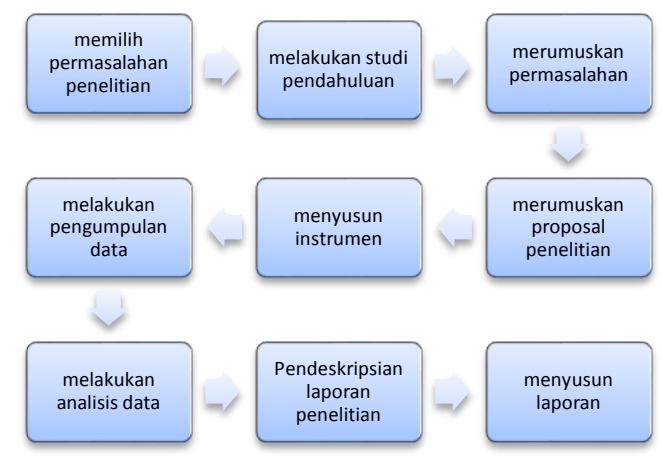

Gambar 3.1.

Diagram Alir Penelitian Identifikasi Minat

(Rekayasa Perangkat Lunak, Jaringan

Komputer, dan Multimedia)

Instrumen yang digunakan dalam penelitian ini berupa angket. Angket dalam penelitian ini tidak memerlukan tahapan validasi ahli. Angket dalam penelitian ini berisi tentang pilihan minat mahasiswa terhadap kompetensi yang ditawarkan. Mahasiswa boleh memilih lebih dari satu kompetensi sesuai dengan minatnya. Cara pengisian angket juga sangat sederhana, yaitu dengan cara memberi tanda centang/silang pada kompetensiRekayasa Perangkat Lunak, Jaringan Komputer, atau Multimedia.

Pada tahap analisis, data isian angket diperoleh dari setiap responden akan dibuat 
rekapitulasinya untuk setiap kompetensi yang diminati. Bilamana ada responden yang memilih lebih dari satu kompetensi, maka akan dimasukkan dalam kategori gabungan. Setekah mendapatkan jumah banyaknya responden/mahasiswa yang berminat pada kompetensi-kompetesni tersebut, maka data tersebut akan diajikan secara deskriptif melalui penyajian data dalam bentuk diagram.

\section{Hasil Penelitian dan Pembahasan}

Sesuai dengan jadwal penelitian adapun penyebaran angket dilaksanakan pada bulan september tepatnya pada tanggal 21 dan 22 september. Jumlah sampel yang mengisi angket terdapat 100 mahasiswa Program Studi Pendidikan Informatika angkatan 2013. Adapun data yang diperoleh sebagai berikut.

\section{Hasil}

Hasil rekapitulasi hasil penjaringan minat mahasiswa Program Studi Pendidikan Informatika angkatan 2013 sesuai dengan tabel di bawah.

Tabel 4. Rekapitulasi Peminatan

\begin{tabular}{|c|c|c|c|}
\hline NIM & RPL & TKJ & MULTI \\
\hline 130631100002 & 0 & 0 & 1 \\
\hline 130631100003 & 0 & 0 & 1 \\
\hline 130631100004 & 1 & 0 & 0 \\
\hline 130631100006 & 0 & 0 & 1 \\
\hline 130631100007 & 0 & 0 & 1 \\
\hline 130631100008 & 0 & 0 & 1 \\
\hline 130631100010 & 0 & 0 & 1 \\
\hline 130631100012 & 0 & 0 & 1 \\
\hline 130631100013 & 0 & 1 & 0 \\
\hline 130631100014 & 0 & 0 & 1 \\
\hline 130631100015 & 0 & 1 & 0 \\
\hline 130631100016 & 0 & 1 & 0 \\
\hline 130631100017 & 0 & 1 & 0 \\
\hline 130631100019 & 0 & 1 & 0 \\
\hline 130631100020 & 0 & 0 & 1 \\
\hline 130631100023 & 0 & 0 & 1 \\
\hline 130631100024 & 0 & 0 & 1 \\
\hline 130631100025 & 0 & 0 & 1 \\
\hline 130631100026 & 0 & 0 & 1 \\
\hline 130631100030 & 0 & 1 & 0 \\
\hline 130631100031 & 1 & 0 & 0 \\
\hline 130631100032 & 0 & 1 & 0 \\
\hline 130631100033 & 0 & 0 & 1 \\
\hline 130631100035 & 0 & 0 & 1 \\
\hline 130631100036 & 0 & 1 & 0 \\
\hline 130631100037 & 0 & 1 & 0 \\
\hline
\end{tabular}

\begin{tabular}{|c|c|c|c|}
\hline NIM & RPL & TKJ & MULTI \\
\hline 130631100038 & 0 & 0 & 1 \\
\hline 130631100039 & 0 & 0 & 1 \\
\hline 130631100040 & 0 & 0 & 1 \\
\hline 130631100041 & 1 & 0 & 0 \\
\hline 130631100042 & 0 & 0 & 1 \\
\hline 130631100043 & 0 & 1 & 0 \\
\hline 130631100044 & 0 & 1 & 0 \\
\hline 130631100045 & 0 & 1 & 0 \\
\hline 130631100046 & 0 & 1 & 0 \\
\hline 130631100048 & 0 & 1 & 0 \\
\hline 130631100052 & 1 & 0 & 0 \\
\hline 130631100054 & 0 & 1 & 0 \\
\hline 130631100055 & 0 & 0 & 1 \\
\hline 130631100056 & 0 & 0 & 1 \\
\hline 130631100057 & 1 & 0 & 0 \\
\hline 130631100058 & 0 & 0 & 1 \\
\hline 130631100059 & 0 & 0 & 1 \\
\hline 130631100062 & 0 & 0 & 1 \\
\hline 130631100064 & 1 & 0 & 0 \\
\hline 130631100065 & 0 & 1 & 0 \\
\hline 130631100068 & 0 & 1 & 0 \\
\hline 130631100070 & 0 & 1 & 0 \\
\hline 130631100071 & 0 & 0 & 1 \\
\hline 130631100072 & 0 & 0 & 1 \\
\hline 130631100075 & 1 & 0 & 0 \\
\hline 130631100076 & 0 & 0 & 1 \\
\hline 130631100079 & 0 & 0 & 1 \\
\hline 130631100080 & 0 & 0 & 1 \\
\hline 130631100081 & 0 & 0 & 1 \\
\hline 130631100082 & 0 & 0 & 1 \\
\hline 130631100083 & 0 & 0 & 1 \\
\hline 130631100084 & 0 & 0 & 1 \\
\hline 130631100085 & 0 & 0 & 1 \\
\hline 130631100088 & 0 & 0 & 1 \\
\hline 130631100089 & 0 & 0 & 1 \\
\hline 130631100090 & 0 & 0 & 1 \\
\hline 130631100092 & 0 & 0 & 1 \\
\hline 130631100093 & 0 & 0 & 1 \\
\hline 130631100094 & 0 & 0 & 1 \\
\hline 130631100095 & 0 & 0 & 1 \\
\hline 130631100096 & 1 & 0 & 0 \\
\hline 130631100097 & 0 & 0 & 1 \\
\hline 130631100098 & 0 & 0 & 1 \\
\hline 130631100101 & 0 & 1 & 0 \\
\hline 130631100104 & 0 & 1 & 0 \\
\hline 130631100105 & 0 & 1 & 0 \\
\hline 130631100108 & 0 & 0 & 1 \\
\hline 130631100109 & 1 & 0 & 0 \\
\hline 130631100110 & 0 & 0 & 1 \\
\hline 130631100111 & 0 & 1 & 0 \\
\hline 130631100112 & 1 & 0 & 0 \\
\hline 130631100113 & 0 & 1 & 0 \\
\hline 130631100114 & 0 & 0 & 1 \\
\hline 130631100115 & 0 & 1 & 0 \\
\hline & & & \\
\hline
\end{tabular}




\begin{tabular}{|c|c|c|c|}
\hline NIM & RPL & TKJ & MULTI \\
\hline 130631100116 & 0 & 0 & 1 \\
\hline 130631100117 & 0 & 1 & 0 \\
\hline 130631100123 & 1 & 0 & 0 \\
\hline 130631100124 & 1 & 0 & 0 \\
\hline 130631100125 & 1 & 0 & 0 \\
\hline 130631100126 & 0 & 0 & 1 \\
\hline 130631100127 & 0 & 1 & 0 \\
\hline 130631100128 & 1 & 0 & 0 \\
\hline 130631100129 & 1 & 0 & 0 \\
\hline 130631100130 & 0 & 0 & 1 \\
\hline 130631100132 & 0 & 0 & 1 \\
\hline 130631100133 & 0 & 1 & 0 \\
\hline 130631100134 & 0 & 0 & 1 \\
\hline 130631100135 & 0 & 0 & 1 \\
\hline 130631100136 & 0 & 0 & 1 \\
\hline 130631100137 & 0 & 1 & 0 \\
\hline 130631100138 & 0 & 0 & 1 \\
\hline 130631100139 & 0 & 1 & 0 \\
\hline 130631100140 & 0 & 0 & 1 \\
\hline 130631100141 & 1 & 0 & 0 \\
\hline 130631100142 & 0 & 0 & 1 \\
\hline JUMLAH & & & \\
MAHASISWA & 16 & 29 & 56 \\
\hline
\end{tabular}

\section{Keterangan:}

1 :memilih kejuruan tersebut

0 :tidak memilih kejuruan tersebut

Sesuai tabel tersebut, jumlah mahasiswa yang minat pada kejuruan Rekayasa Perangkat Lunak (RPL) terdapat 16 mahasiswa, untuk kejuruan Teknik dan Komputer Jaringan (TKJ) terdapat 29 mahasiswa dan untuk kejuruan Multimedia terdapat 56 mahasiswa.

Adapaun penyajian dalam bentuk diagram lingkarannnya sebagai berikut.

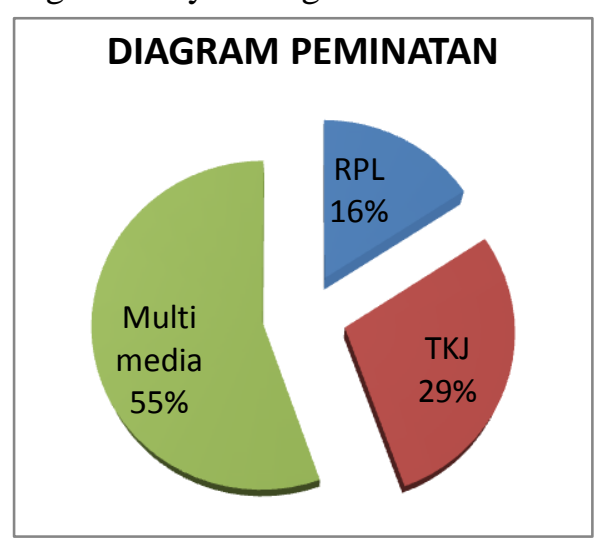

Gambar4.1 Diagram Peminatan.

Dari Gambar 4.1 terlihat jelas bahwa, peminatan mahasiswa terhadap kejuruan

multimedia lebih banyak dari pada peminatan kejuruan Teknik dan Komputer Jaringan (TKJ) maupun Rekayasa Perangkat Lunak (RPL) yaitu sebesar 55\%. Sedangkan urutan kedua adalah untuk peminatan kejuruan Teknik dan Komputer Jaringan (TKJ) sebesar 29\% dan urutan terakhir adalah untuk Rekayasa Perangkat Lunak (RPL) sebesar $16 \%$.

\section{Pembahasan}

Penyebaran angket peminatan yang dilaksanakan kepada 100 sample mahasiswa Program Studi Pendidikan Informatika menunjukkan bahwa peminatan kejuruan multimedia jauh lebih banyak dari pada peminatan kejuruan Teknik dan Komputer Jaringan (TKJ) maupun Rekayasa Perangkat Lunak (RPL). Dengan data yang telah dipresentasekan yaitu sebesar $55 \%$ atau diminati lebih dari separuh mahasiswa. Adapun alasan - alasan mahasiswa memilih kejuruan ini rata - rata dikarenakan multimedia lebih aplikatif, menyenangkan, dapat bebas berkreasi dan hasilnya nyata.

Sedangkan untuk peminatan kejuruan Teknik dan Komputer Jaringan (TKJ) yang menduduki urutan kedua pemintan mahasiswa yaitu sebesar $29 \%$, mengemukakan bahwa rata - rata alasan mereka dikarenakan memiliki latar belakang pendidikan SMK Teknik dan Komputer Jaringan (TKJ).

Untuk peminatan kejuruan Rekayasa Perangkat Lunak (RPL) yang menduduki urutan terbawah atau terakhir pemintan mahasiswa yaitu sebesar $16 \%$, mengemukakan bahwa rata - rata alasan mereka sama dengan peminatan kejuruan Teknik dan Komputer Jaringan (TKJ) yaitu dikarenakan memiliki latar belakang pendidikan SMK Rekayasa Perangkat Lunak (RPL).

\section{Kesimpulan dan Saran Kesimpulan}

Adapun simpulan yang dapat dimbil dalam penelitian ini adalah:

1. Peminatan mahasiswa terhadap kejuruan multimedia lebih banyak dari pada 
peminatan kejuruan Teknik dan Komputer Jaringan (TKJ) maupun Rekayasa Perangkat Lunak (RPL) yaitu sebesar 55\%, dengan alasan rata - rata dikarenakan multimedia lebih aplikatif, menyenangkan, dapat bebas berkreasi dan hasilnya nyata.

2. Urutan kedua adalah peminatan kejuruan Teknik dan Komputer Jaringan (TKJ) sebesar 29\% dengan alasan rata - rata dikarenakan mahasiswa memiliki latar belakang pendidikan SMK Teknik dan Komputer Jaringan (TKJ), dan

3. Urutan terakhir adalah untuk peminatan kejuruan Rekayasa Perangkat Lunak (RPL) sebesar $16 \%$ dengan alasan rata - rata karena mahasiswa memiliki latar belakang pendidikan SMK Rekayasa Perangkat Lunak (RPL).

\section{Saran}

1. Terdapat proporsi mata kuliah yang seimbang antara peminatan Multimedia, Teknik dan Komputer Jaringan (TKJ), dan Rekayasa Perangkat Lunak (RPL) sehingga terjadi peminatan yang merata.

2. Penggunaan model dan strategi pembelajaran yang menarik terutama pada mata kuliah yang berhubungan dengan peminatan Teknik dan Komputer Jaringan (TKJ), dan Rekayasa Perangkat Lunak (RPL).

\section{Daftar Pustaka}

Peraturan Menteri Nomor 064 Tahun 2014. sumber: http://www.kemdiknas.go.id/ pada 9 September 2015.

Kemdikbud. 2013. Peminatan peserta Didik. Pdf diakses pada 20 September 2015

Siregar, Syofian. 2014. Statistik Parametrik Untuk Penelitian Kuantitatif. Jakarta: Bumi Aksara.

Sugiyono. 2014. Statistika Untuk Penelitian. Bandung: Alfabeta.
TIM. 2014. Borang Akreditasi Program Studi pendidikan Informatika FKIP UTM. Bangkalan: Dokumen Prodi. 